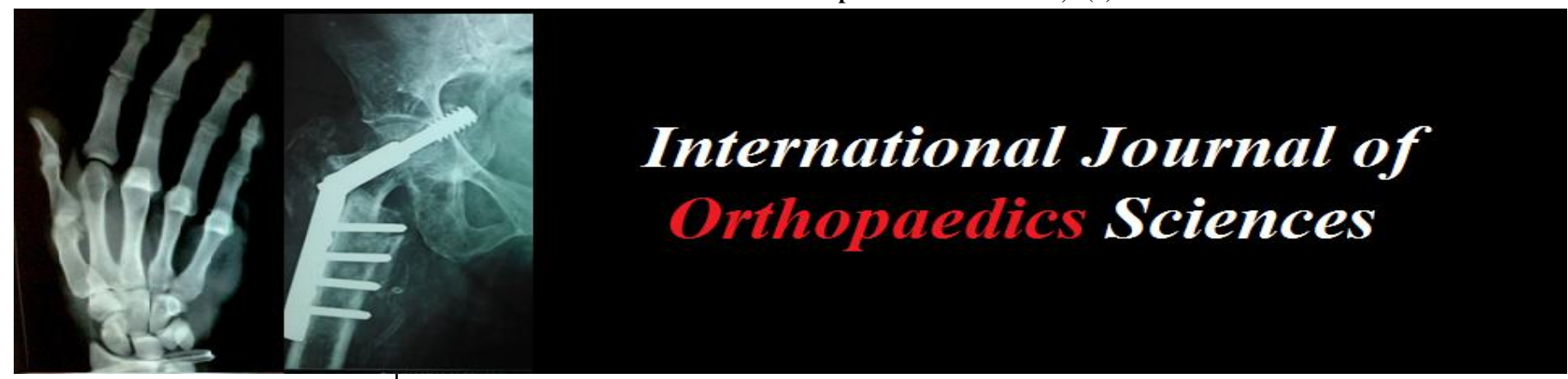

E-ISSN: 2395-1958

P-ISSN: 2706-6630

IJOS 2020; 6(2): 501-504

(C) 2020 IJOS

www.orthopaper.com

Received: 22-02-2020

Accepted: 24-03-2020

Vivek M Sodhai

M.S. Orthopaedics, Pediatric

Orthopaedic Fellow, Sancheti Institute of Orthopaedics and

Rehabilitation, Pune,

Maharashtra, India

Sandeep A Patwardhan

Professor and Head, Department

of Pediatric Orthopaedics,

Sancheti Institute of

Orthopaedics and

Rehabilitation, Pune,

Maharashtra, India

Arvind Kumar

M.S. Orthopaedics Lecturer,

Sancheti Institute of

Orthopaedics and

Rehabilitation, Maharashtra,

India

Parag K Sancheti

Professor and Head, Sancheti

Institute of Orthopaedics and

Rehabilitation, Pune,

Maharashtra, India

Ashok K Shyam

Head of Research Department,

${ }^{1}$ Sancheti Institute of

Orthopaedics and

Rehabilitation, Pune,

Maharashtra, India

2Indian Orthopaedic Research

Group, Thane, Maharashtra,

India
Corresponding Author:

Vivek M Sodhai

M.S. Orthopaedics, Pediatric

Orthopaedic Fellow, Sancheti

Institute of Orthopaedics and

Rehabilitation, Pune,

Maharashtra, India

\section{Quantification of differences in lower-limb appearance between idiopathic clubfeet treated by ponseti casting method versus normal feet in young children}

\author{
Vivek M Sodhai, Sandeep A Patwardhan, Arvind Kumar, Parag K \\ Sancheti and Ashok K Shyam
}

DOI: https://doi.org/10.22271/ortho.2020.v6.i2h.2090

Abstract: Despite excellent functional correction of club foot, the appearance of the treated lower-limb differs morphologically from normal lower-limbs which has been described qualitatively in the past. The purpose of this study is to quantify the lower-limb appearance between idiopathic ponseti-treated clubfeet versus normal feet in terms of foot length, calf girth and internal tibial torsion in a group of young

children.

Materials and methods: 49 club foot patients (29 unilateral, and 20 bilateral) below the age of 12 months were treated using the Ponseti casting method. When patients reached walking age (average 14 months), the evaluation was done using the Pirani score. Upon a score of 0 (indicating full correction), the lower-limb appearance was defined by foot length, calf girth, and internal tibial torsion measurements.

Results: Of the 29 patients with unilateral clubfoot (age: $14 \pm 3$ months), $86 \%$ had smaller foot length $(11.9 \pm 0.7 \mathrm{~cm}, \mathrm{p}<0.05), 69 \%$ had smaller calf girth $(17.1 \pm 1.7 \mathrm{~cm}, \mathrm{p}<0.05)$ and $79 \%$ had larger internal tibial torsion $\left(16.1^{\circ} \pm 3.7^{\circ}, \mathrm{p}<0.001\right)$ in comparison to normal lower-limbs $(\mathrm{n}=19)$. Of the 20 patients with bilateral clubfeet (age: $14 \pm 3$ months), $100 \%$ had smaller foot length $(12.0 \pm 0.7 \mathrm{~cm}, \mathrm{p}<$ $0.05), 60 \%$ had smaller calf girth $(17.1 \pm 1.4 \mathrm{~cm}, \mathrm{p}<0.05)$ and $74 \%$ had larger internal tibial torsion $\left(15.3^{\circ} \pm 3.9^{\circ}, \mathrm{p}<0.001\right)$ in comparison to age-matched normal lower-limbs $(\mathrm{n}=19)$. However, when comparing all treated lower-limbs $(n=49)$ to normal lower-limbs $(n=20), 82 \%$ had significant difference in all these parameters.

Conclusion: Children with Idiopathic Club Feet treated with Ponseti exhibit significant quantitative differences in terms of smaller foot length, smaller calf-girth and larger internal rotation as compared to normal individuals. Prior counselling of parents regarding these differences in unilateral cases is recommended.

Keywords: Calf girth, club foot, foot length, quantitative measurements, tibial torsion

\section{Introduction}

Congenital talipes equinovarus (CTEV), commonly known as 'club foot,' is a developmental disorder with an incidence of approximately 1-3 per 1000 live births worldwide. Club foot is characterised by equinus, varus, and internal rotation of the os calcis beneath the talus, along with adductus, cavus and supination of the mid- and forefoot ${ }^{[1]}$. There is a 2.5:1 male to female ratio in the incidence of club foot, with approximately $50 \%$ of cases occurring bilaterally and $24.4 \%$ of affected individuals have a family history of CTEV ${ }^{[2]}$. Genetic and environmental factors have been suggested to cause club foot, but the etiology remains largely unknown ${ }^{[3]}$.

Previously, techniques for correction of the deformity included extensive operative soft tissue release or other surgical methods. Currently, the conventionally accepted conservative treatment of choice is serial manipulation and casting described as the Ponseti method ${ }^{[1]}$. This method provides a lower complication rate, less pain, and better function as the patient ages as compared to operative treatment ${ }^{[4]}$. It has been reported to have short-term success rates approaching $90 \%$, with equally impressive long-term results irrespective of the severity of the deformity at presentation ${ }^{[5,6]}$. 
Upon treatment of club foot (surgical or otherwise), there is a recognized difference in the appearance of the treated 'lowerlimb' (which we define as the area from the knee to the end of the foot) compared to normal. We believe that despite a good Pirani score, parents had concerns regarding foot size, calf appearance and gait pattern in children. We identified the parent's problem with regards to the following 3 parameters: 1) Difference in foot length 2) Difference in calf girth. 2) The difference in gait essentially secondary to tibial torsion. Generally, previous studies have described this difference in only subjective or qualitative terms, noting a smaller calf girth, foot length and larger internal tibial torsion $[7,8,9,10,11]$. Even with some accurately measuring features in like calf volume and tibial torsion, lower-limb appearance for young children, a key group that undergo treatment, has not been sufficiently described. Moreover, with most studies focusing on post-surgical treatment, assessment of the lower-limb after Ponseti treatment, now the more preferred method, has not been properly addressed either.

We tested the hypothesis that there are notable differences in the appearance of lower limb of Ponseti-treated idiopathic club-foot children in terms of calf girth, foot length and internal tibial torsion despite good pirani score. Ultimately, we hope that such research will help in effective counseling of parents of children affected with club foot prior to the start of the treatment.

\section{Material and methods}

Our prospective study was conducted from November 2015 to November 2017 at our Institute. Written informed consent was taken from the parents of all patients. The study protocol was approved by the Institutional Ethics Committee.

Both bilateral and unilateral primary idiopathic club foot children up to 12 months of age were included in this study. Excluded were those with a relapsed club foot, with a secondary equinovarus deformity (eg. spina bifida, meningomyelocele), and/or with any surgical intervention for club foot. Out of the 150 patients screened, 65 qualified and were included in the study with informed consent. Of the 65 , 50 came to follow-ups, one of which was removed from data analysis due to noncompliance with the casting program. The average age of the 49 patients included for analysis was $14 \pm$ 3 months, with 35 males and 14 females in the group. Of the 49 patients, 29 were unilaterally affected and 19 bilaterally.

\subsection{Treatment \& measurement}

All idiopathic clubfoot patients were treated by a single paediatric orthopaedic specialist from 2015 to 2017 with standard protocol for Ponseti casts. The completion of treatment was determined by a Pirani score of 0 (indicating no deformity). All patients but two received Pirani scores of 0 at one year of age. These two patients received tenotomies and further casting (part of the Ponseti method) until fully treated. Upon completion of treatment, the calf girth, foot length and tibial torsion of the treated lower-limbs were measured. Calf girth, defined by the level of maximum girth around the calf muscle, was measured with standard measurement tape. Foot length, defined by the distance from the heel to the tip of the greater toe, was determined by attaining a footprint measurement with a standard measuring tape. Tibial torsion, defined as the thigh-foot angle, was determined with measurement by a goniometer ${ }^{[12]}$.

20 patients ( 15 male, 5 female) unaffected by club foot with an average age of 15 months were included as a control group. Patients with upper limb anomalies, but without any history of neurological disorders were included in the control group.

\subsection{Statistical analysis}

All data were screened using Grubb's outlier test, and one control patient was removed, leaving 19 control patients and 20 bilateral patients for data analysis. Foot length, calf girth, and internal tibial torsion did not differ significantly by age as determined by statistical regression, and so the treated lowerlimbs and control lower-limbs $(n=19)$ for all age groups were compared using standard two-tailed t-tests. For analysis, either the left or right side of the bilateral patients was randomly chosen for data analysis $(n=20)$, as there were no significant differences between the two sides. Treated unilateral lower-limbs $(n=29)$ and randomly chosen bilateral lower-limbs $(n=20)$ were not statistically different and were thus compiled into a variable representing all treated limbs (n $=49$ ).

\section{Results}

Of the 29 patients with unilateral clubfoot (age: $14 \pm$ 3 months $), 86 \%$ had smaller foot length $(11.9 \mathrm{~cm} \pm 0.7 \mathrm{~cm}, \mathrm{p}<$ $0.05), 69 \%$ had smaller calf girth $(17.1 \mathrm{~cm} \pm 1.7 \mathrm{~cm}, \mathrm{p}<$ $0.05)$, and $79 \%$ had larger internal tibial torsion $\left(16.1^{\circ} \pm 3.7^{\circ}\right.$, $\mathrm{p}<0.001)$ in their Ponseti-treated lower-limb $(\mathrm{n}=29)$ compared to normal lower-limbs $(n=19)$. (Figure 1A)

Of the 20 patients with bilateral clubfeet (age: $14 \pm 3$ months), $100 \%$ had smaller foot length $(12.0 \mathrm{~cm} \pm 0.7 \mathrm{~cm}, \mathrm{p}<0.05)$, $60 \%$ had smaller calf girth $(17.1 \pm 1.4 \mathrm{~cm} \mathrm{p}<0.05)$, and $74 \%$ had larger internal tibial torsion $\left(15.3^{\circ} \pm 3.9^{\circ}, \mathrm{p}<0.001\right)$ in their average Ponseti-treated lower-limbs $(n=19)$ compared to normal lower-limbs $(n=19)$. (Figure 1B)
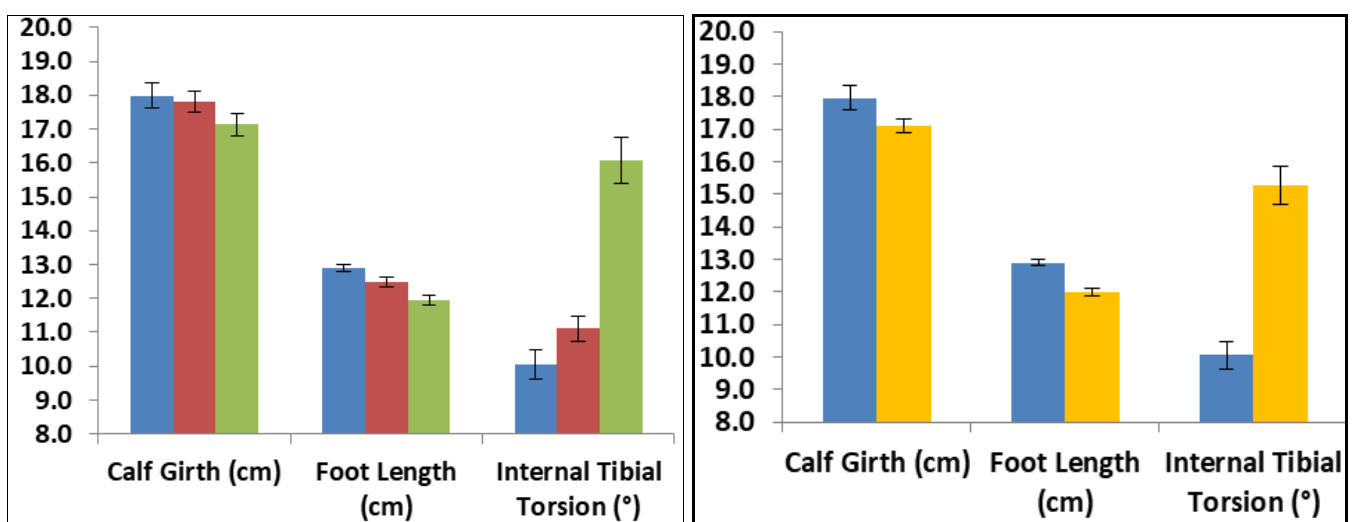

Fig 1: Difference in Appearance between Affected (Treated) and Normal Lower Limbs: A Affected unilateral lower limbs (Uni $\mathrm{A}, \mathrm{n}=29)$ and unaffected unilateral lower limbs (Uni, $n=29)$ versus control $(n=38)$, B Affected bilateral lower-limbs $(n=42)$ versus control $(n=38)$. 


$$
\begin{array}{ll}
\text { Treated VS Control } & \multicolumn{2}{l}{\mathrm{Uni}_{\mathrm{A}} \text { VS UniU }} \\
* \quad \mathrm{P}<.05 & \dagger \quad \mathrm{p}<.01 \\
* * \quad \mathrm{P}<.001 & \dagger \dagger \quad \mathrm{p}<.001
\end{array}
$$

- Control

- Unilateral Affected

\section{- Unilateral Unaffected}

Bilateral Affected
However, when comparing all treated lower-limbs $(n=49)$ to normal lower-limbs $(\mathrm{n}=20), 82 \%$ had smaller calf-girth $(\mathrm{p}<$ $0.05)$, smaller foot size $(\mathrm{p}<0.001)$, and larger internal tibial torsion $(\mathrm{p}<0.001) .98 \%$ of patients experienced such differences in at least one of three parameters, and 54\% had

\begin{tabular}{|c|c|c|c|c|c|c|c|c|}
\hline & \multicolumn{2}{|c|}{ Calf Girth } & \multicolumn{2}{|c|}{ Foot Length } & \multicolumn{2}{|c|}{ Internal Tibial Torsion } & \multicolumn{2}{|c|}{ Percent Affected } \\
\hline & Average $(\mathrm{cm})$ & $\%$ & Average $(\mathrm{cm})$ & $\%$ & Average $\left(^{0}\right)$ & $\%$ & In 1p & In all 3p \\
\hline Uniu & $17.8( \pm 1.7)$ & $54 \%$ & $12.5( \pm 0.7) *$ & $57 \%$ & $11.1( \pm 1.9) *$ & $29 \%$ & $79 \%$ & $0 \%$ \\
\hline Uni $_{A}$ & $17.1( \pm 1.7) * *$ & $69 \%$ & $11.9( \pm 0.7) *$ & $86 \%$ & $16.1( \pm 3.7) *$ & $79 \%$ & $97 \%$ & $48 \%$ \\
\hline $\mathrm{Bi}_{\mathrm{A}}$ & $17.1( \pm 1.4) * *$ & $60 \%$ & $12.0( \pm 0.7) *$ & $100 \%$ & $15.3( \pm 3.9) *$ & $74 \%$ & $90 \%$ & $45 \%$ \\
\hline Control & $18.0( \pm 1.6)$ & & $12.9( \pm 0.4)$ & & $10.1( \pm 1.9)$ & & & \\
\hline
\end{tabular}
expected differences in all parameters. (Table 1)

Table 1: Average Measurements of Affected (Treated) Lower-Limbs and Percent Affected per Lower-limb Appearance Parameter: Average measurements for each parameter in the given groups. Additionally, reported are the percentage of lower-limbs ('percent affected') that were different than in the direction that we observed (less foot length, less calf girth, and more internal tibial torsion). The labels ' $1 p$ ' and ' $3 p$ ' denote the amount of cases for which the lower-limbs were different in one and all three parameters respectively.

\section{Discussion}

Various authors have studied the qualitative differences in limb appearance in clubfeet patients treated with Ponseti and surgical methods. Foot length, calf girth, and internal tibial torsion have been studied separately or in combination with each other. Few authors focused on the calf girth difference in clubfeet patients $[7,8,9,13]$. Aronson $\mathrm{J}$ et al. found $10 \%$ decrease in calf girth in 29 patients unilateral idiopathic clubfoot patients treated with cast and soft tissue release compared with control 23 patients evaluated with morphometry ${ }^{[7]}$. Chan KT et al. found $4 \mathrm{~cm}$ difference in the calf circumference in the 37-year-old treated club as compared to the normal. MRI confirmed a decrease in the calf muscle mass ${ }^{[8]}$. Shimode $\mathrm{K}$ et al. evaluated the limb length and calf discrepancy in 38 unilateral congenital clubfeet treated with serial casting method and surgery in some patients using ultrasonography. They concluded that tibial length and calf girth was significantly less in those treated with surgery, femur length and thigh girth were affected the least. They also concluded that these changes do not tend to change with growth on long term follow-up ${ }^{[9]}$. Fulton $\mathrm{Z}$ et al. compared the calf circumference of unilateral clubfeet patients treated with Ponseti method and extensive surgery and concluded that the calf circumference is significantly smaller in patients treated with extensive surgery than those treated with ponseti method with or without percutaneous tenotomy ${ }^{[13]}$.

Certain other authors showed their results of torsional measurements in clubfeet patients ${ }^{[10,11]}$. Krishna $\mathrm{M}$ et al. found less average external torsion in unilateral clubfeet cases compared with control group patients in different age group patients. Torsion measured with ultrasonography. They concluded that the relative internal tibial torsion in CTEV suggest that the pathology is not confined only to the affected foot ${ }^{[10]}$. Reikeras O et al. used CT scan to measure internal rotation and found less average external rotation in clubfeet patients ${ }^{[11]}$. Kesemenli et al. utilized anthropometric measurements to evaluate the results of three treatments methods (conservatively treated, surgically treated and combined treatment) on club feet. Authors concluded that discrepancy may not be dependant only on treatment method but also on the severity of the clubfeet deformity at presentation ${ }^{[14]}$. Gamble et al. evaluated 93 children treated with posteromedial release and ponseti method and found a mean calf size difference of $9.83 \%$ and mean foot size difference of $8.70 \%$. They also concluded that smaller size of the treated clubfeet can be attributed to the condition rather than the type of treatment ${ }^{[15]}$. Recently, Agrawal and Rastogi measured foot length and width in unaffected, unilateral and bilateral club feet and concluded that bilateral were significantly smaller than unaffected feet of normal healthy children [foot length $0.8 \mathrm{~cm}$; p-value $=0.03$; foot width $0.2 \mathrm{~cm}$; $\mathrm{p}$-value $=0.03]$. The unilateral ponseti treated feet sizes were comparable with the unaffected feet during the treatment on braces ${ }^{[16]}$.

Our study is in concordance with the previous studies and show significant differences in quantitative appearances of the foot in terms of foot length, calf girth and tibial torsion. The study shows that despite pirani score of zero, the treated lower limb exhibits smaller foot length, smaller calf girth and excessive internal rotation as compared to control group. These changes important in unilateral cases which are of significant concern to parents.

There are certain limitations to the study. There are chances of inter-observer variations in the measurements of these parameters which were minimized by allowing a single person to measure these parameters using the standard protocol for all patients. These patients need long-term follow-up to see whether there are any changes in these anthropometric measurements depending on the growth pattern, compliance to bracing and rehabilitation. We dedicated our study to the quantification of anthropometric measurements including all three parameters (foot length, calf girth, and tibial torsion) and the differences in unilaterally as well as bilaterally affected clubfeet in comparison to normal lower limbs. Through our study, we intend to counsel the parents before starting the treatment that in spite of the full correction with a Pirani score of 0 , there is a chance of quantitative difference in foot length, calf girth, and internal tibial torsion, especially in unilateral cases.

\section{Conclusion}

We conclude that there is a significant difference between the appearance of the Ponseti-treated lower-limbs and normal lower-limbs in both unilaterally and bilaterally affected clubfeet patients. The treated lower-limb exhibits a smaller foot length, smaller calf-girth and larger internal tibial torsion by the same magnitude in both bilateral and unilateral cases. These findings are of paramount importance in counseling the parents of clubfoot patients prior to the start of the treatment 
in unilateral cases. We believe these parameters will help in the formation of a scoring system for better evaluation of treated clubfeet patients.

\section{References}

1. Ponseti IV. Current concepts review: treatment of congenital club foot. J Bone J Surg. Am. 1992; 74(3):448-454.

2. Lochmiller CJD. Genetic Epidemiology study of idopathic talipes equinovarus. Am J Med Genet. 1998; 79:90-96.

3. Wynne-Davies R. Family Studies and the cause of congenital clubfoot. J Bone Joint Surg. 1964; 46-B:445463.

4. Lehman WB, Mohaideen A. A method for the early evaluation of the Ponseti (Iowa) technique for the treatment of idiopathic clubfoot. J Pediatr Orthop. 2003; 12(2):133-40.

5. Dobbs MB, Rudzki JR. Factors predictive of outcome after use of the Ponseti method for the treatment of idiopathic clubfeet. J Bone Joint Surg. Am. 2004; 86:2227.

6. Ponseti IV, Zhivkov M. Treatment of the complex idiopathic clubfoot. Clin Orthop Relat Res. 2006; 451:171-176.

7. Aronson J, Puskarich CL. Deformity and disability from treated clubfoot. J Pediatr Orthop, 1990; 10(1):109-19.

8. Chan KT, Hurley RA. Improving the clinical assessment of leg muscle in adult clubfoot using magnetic resonance imaging: a case report. J Clin Neuromuscul Dis. 2002; $4(1): 23-6$.

9. Shimode K, Miyagi N. Limb length and girth discrepancy of unilateral congenital clubfeet. J Pediatr Orthop B. 2005; 14(4):280-4.

10. Krishna M, Evans R. Tibial torsion measured by ultrasound in children with talipes equinovarus. $\mathrm{J}$ Bone Joint Surg. Br. 1991; 73(2):207-10.

11. Reikeras O, Kristiansen LP. Reduced tibial torsion in congenital clubfoot: CT measurements in 24 patients. Acta Orthop Scand. 2001; 72(1):53-6.

12. Staheli LT, Corbett M. Lower extremity rotational problems in children. Normal values to guide management. J. Bone Joint surg. 1985; 67-A:39-47.

13. Fulton Z, Briggs D. Calf circumference discrepancies in patients with Unilateral Clubfoot: Ponseti Versus Surgical Release. J Pediatr Orthop. 2015; 35:403-406.

14. Kesemenli CC, Kapukaya A. Anthropometric Study of Patients Treated for Clubfoot. J Pediatr Orthop. 2003; 23:498-502.

15. Gamble J, Batista E. How small is the leg and foot in Unilateral Clubfoot. www.bjjprocs.boneandjoint.org.uk/content/94B/SUPP_XXI/34, 2018.

16. Agarwal A and Rastogi A. Anthropometric measurements in Ponseti treated clubfeet. SICOT-J. 2018; 4:19. 